\title{
Ruthenium isotopic evidence for a missing late accretion component in the mantle source of Pilbara craton
}

\author{
M. FISCHER-GÖDDE', C. MÜNKER', H. BECKER², W.D. \\ MAIER $^{3}$, M. VAN KRANENDONK ${ }^{4}$, H. SMITHIES ${ }^{5}$
}

Inst. f. Geol. und Min., Univ. of Cologne, Germany

'Inst. f. Geol. Wissenschaften, FU Berlin, Germany

${ }^{3}$ School of Earth and Ocean Sciences, Cardiff Univ., UK

${ }^{4}$ Austral. Centre f. Astrobiology, UNSW, Sydney, Australia

${ }^{\varsigma}$ Geol. Surv. of Western Australia, East Perth WA, Australia

Early Archean komatiites from the Pilbara craton (Australia) exhibit lower highly siderophile element (HSE) concentrations than observed for younger komatiite formations [1]. The significant HSE depletion in 3.5-3.2 Gaold komatiites from Pilbara suggests that these lavas derive from a mantle source that had not yet fully equilibrated with late accreted material [1]. This interpretation seems to be corroborated by the presence of ${ }^{182} \mathrm{~W}$ excesses reported for some mafic rocks from Pilbara [2]. However, the ${ }^{182} \mathrm{~W}$ excesses do not provide unequivocal evidence for incomplete mixing of late accreted material because they may also reflect early mantle differentiation processes [3]. In this regard, mass-independent $\mathrm{Ru}$ isotope variations represent a more powerful and indicative tool to identify primordial mantle heterogeneities arising from incomplete mixing of the ambient mantle with late accreted material [4]. Here we determined the $\mathrm{Ru}$ isotope compositions of komatiites from Pilbara and report new ${ }^{187} \mathrm{Os} /{ }^{188} \mathrm{Os}$ and HSE contration data for the same rocks.

Komatiites from the Ruth Well, Louden/Bookingara and Coonterunah formations show a relative excess in ${ }^{100} \mathrm{Ru}$ of 23 parts per million compared with the modern mantle composition. The magnitude of the ${ }^{100} \mathrm{Ru}$ excess in these rocks is the same as observed for ultramafic rocks from SW Greenland [4]. The ${ }^{100} \mathrm{Ru}$ excess represents a mass-indepenedent anomaly of nucleosynthetitc origin and provides unambiguous evidence that the Pilbara komatiites derive from a mantle source that did not have the full equivalent of late accreted material compared to the modern mantle. Futhermore, the ${ }^{100} \mathrm{Ru}$ excess also indicates that the mantle source of these rocks contains a fraction of Ru that was not completely stripped from the mantle during the latest stages of core formation. Otherwise no $\mathrm{Ru}$ isotope anomaly could be observed.

[1] Maier et al. (2009) Nature 460, 620-623. [2] Archer et al. (2019) EPSL 528, 115841. [3] Tusch et al. (2020) this meeting. [4] Fischer-Gödde et al. (2020) Nature, in press. 